DOI 10.5216/ia.v46i2.65057

\title{
EDUCAÇÃO DO CAMPO E PROJETOS SOCIAIS: UMA VISÃO DE INTERESSES
}

\author{
Silas Cleiton Soligo \\ LeANDRO Carlos Ody \\ Universidade Federal da Fronteira Sul (UFFS), Erechim, Rio Grande do Sul, Brasil
}

\begin{abstract}
Resumo: Este estudo se situa na investigação entre a relação dos projetos sociais desenvolvidos nas escolas campesinas por empresas do ramo agroindustrial e a perspectiva da luta de classes proposta pelo movimento de Educação do Campo. Para desenvolvê-lo, utilizamos a metodologia de caráter qualitativo pautada na análise bibliográfica. Destacamos o alcance de conquistas por parte dessa modalidade nas últimas décadas. Todavia, evidenciamos os impactos que projetos capitalistas causam nas escolas rurais. Nesse sentido, é importante que essas instituições e suas redes de ensino estabeleçam parceiras no intuito de capacitar seus educadores a instaurarem práticas de fortalecimento de uma educação que esteja voltada às necessidades camponesas.
\end{abstract}

Palavras-chave: Escola do Campo. Educação. Pensamento Hegemônico. Ciências Naturais.

\section{CONSIDERAÇÕES INICIAIS}

Quando nos desafiamos a pensar a educação, percebemos quão complexa é essa área do conhecimento humano. Nos deparamos com conceitos teóricos, diferentes práticas e legislações que orientam aquilo que é realizado nos espaços escolares, bem como diferentes contextos onde ela acontece. $O$ fato é que cabe a ela ser o componente relevante para a promoção do desenvolvimento da nação e do atendimento das necessidades dos grupos que constituem a sociedade.

Todavia, essa concepção ainda encontra desafios para se consolidar, principalmente quando olhamos para as realidades carentes, dentre elas a realidade das populações campesinas. Essas populações durante muito tempo foram negligenciadas pelos governantes em muitos aspectos, inclusive no educacional, mas quando conseguiram se articular, principalmente através de movimentos sociais do campo, encontraram formas de resistência e propuseram maneiras diferenciadas para seus contextos.

Por meio dessa articulação, várias conquistas foram alcançadas no âmbito das políticas públicas federais, já que os últimos governos se identificavam com a relevância que a Educação do Campo tem na promoção da formação das pessoas nesse espaço. No entanto, ainda é forte a influência dos interesses capitalistas, principalmente entre grupos caracterizados atuantes no campesinato. Sob esse viés enquadra-se a mudança abrupta de governo em 2016. Essa mudança trouxe diversos retrocessos ao meio educacional brasileiro, especialmente os ligados aos cortes orçamentários, que, em específico à Educação do Campo, levaram ao fechamento de vagas nos cursos, ao 
incentivo de fechamento das escolas do campo e a uma crescente omissão para com o camponês.

Nesse sentido, a educação, ao invés de emancipar o povo, acaba hegemonizando-o. A globalização impõe regras voltadas às suas necessidades, onde formar o estudante para a vida consiste em integrá-lo ao espaço industrial, caso ele esteja no meio urbano ou, caso seja ele do meio rural, à cadeia do agronegócio.

Assim, a problemática do nosso estudo buscou investigar a relação entre projetos sociais desenvolvidos nas escolas do campo por empresas do ramo agroindustrial e a perspectiva da luta de classes proposta pelo movimento de Educação do Campo. Tratar sobre esse questionamento se torna importante na razão de demonstrar as expressões reproduzidas por tais projetos, bem como questioná-las na finalidade de fomentarem ações relevantes ao referido contexto.

Portanto, o objetivo deste ensaio é trazer uma reflexão que articule a Educação do Campo, o ensino das Ciências da Natureza e a implantação de projetos sociais nas escolas do campo brasileiras. Olhar para esse enfoque revela a importância de valorizarmos o espaço rural como um ambiente onde o conhecimento se materializa em forma de vida, pois a Ciência se manifesta no encontro das relações sócio produtivas que engendram os diversos contextos sociais.

A metodologia utilizada foi de cunho qualitativo, pautada no caráter bibliográfico. Apoiamos o trabalho em três momentos principais: o primeiro, apresenta os aspectos históricos relacionados ao movimento da Educação do Campo; o segundo, trata da conjuntura dos projetos sociais apoiados sob a Lei de Responsabilidade Social das Sociedades Empresariais e a correlação com a gênese hegemônica capitalista; no último, evidenciamos as considerações finais a respeito da temática abordada.

\section{EDUCAÇÃO DO CAMPO: BASES HISTÓRICAS E FUNDAMENTOS}

A educação é uma das ferramentas mais importantes no meio social, pois, aliada às políticas públicas, possibilita ao cidadão buscar e efetivar os seus direitos. Entretanto, com a negação do acesso a uma educação de qualidade imposta às classes populares, ela se tornou um campo de disputa, onde é necessário estar mobilizado para garantir o protagonismo social.

A Educação do Campo tem suas raízes na Educação Popular, onde historicamente se preconizava o ensino alfabetizador, baseado em princípios voltados à cultura popular de cada local. Assim, os embasamentos principais partem do senso comum, mas buscam descobrir uma teoria presente na prática local, a qual acaba por internalizar naturalmente o conhecimento científico e unitário (GADOTTI, 2012).

Com a expansão do processo de êxodo rural durante as décadas de 1960 e 1970, o Estado Brasileiro concebe a Educação Rural no intuito de conter o crescimento das favelas, pensando numa proposta que se destinava a amparar a manutenção das escolas na zona rural (BRASIL, 2007). Além do mais, o pleno desenvolvimento industrial e a modernização da agricultura se articulavam, criando-se o ensino agrícola para aproveitar a mão de obra desse contexto, bem como desenvolver as novas tecnologias, 
SOLIGO, S. C.; ODY, L. C.

o que possibilitaria trazer um horizonte capaz de impulsionar a economia do país (CECHIN; VIEIRA, 2004).

O resultado desse desejo trouxe mudanças nos valores e atitudes da sociedade, desconsiderando veementemente o mundo campesino, enfatizando a progressiva relação de dependência dos agricultores dos agroquímicos, das máquinas, com a educação voltada para a assistência técnica e para a extensão rural (SANTOS, 2018). Ou seja, o mundo rural perde o posto de soberano na produção de alimentos saudáveis e passa a ser apenas um local de produção das matérias-primas do capital.

Já com a retomada da democracia na década de 1980, o país vivencia mudanças em sua conjuntura política e econômica. Todavia, o enfrentamento dos efeitos da crise internacional promoveu a estagnação do PIB e o aumento da dívida externa, interferindo negativamente nos níveis de emprego e renda dos brasileiros (OMETTO; FURTUOSO; SILVA, 1995).

No meio rural, as dificuldades enfrentadas recaíam no endividamento, na falta de acesso às tecnologias e na baixa qualidade de vida dos agricultores. Do mesmo modo, a educação esteve influenciada, pois sofria com a "[...] ausência de investimentos no aparelhamento da escola e na qualificação dos professores" (GRITTI, 2007, p. 32).

Mesmo assim, com o apoio de diferentes organizações ${ }^{1}$ ligadas à Educação Popular e também com a criação do Movimento dos Trabalhadores Sem Terra (MST) em 1984, a população rural encontrou oportunidades para discutir as suas necessidades educacionais (SANTOS, 2018). Trabalhar em torno das concepções de Paulo Freire foi o alicerce principal da política educacional do MST, que visa tratar a educação como práxis fundada na criatividade, na ação, na reflexão e na transformação do ser humano (TIEPOLO, 2015).

Outros aspectos em destaque desse movimento centralizam-se na organização baseada na Pedagogia da Alternância, na qual a divisão do tempo ocorre entre as atividades realizadas na escola e no ambiente familiar, o que possibilita a construção educativa omnilateral ${ }^{2}$ humana (BRASIL, 2007). Além disso, a itinerância conota uma importante relevância à escola; isto é, se os trabalhadores forem expulsos dos acampamentos, a instituição os acompanha ao seu destino (TIEPOLO, 2015).

Na década de 1990, têm-se os marcos que viabilizaram os avanços nas políticas relacionadas à Educação do Campo. Primeiramente, a criação da Lei de Diretrizes e Bases da Educação Nacional, n 9.394 de 1996, veio estabelecer uma base comum a todo o território brasileiro, determinando a adequação da educação e do calendário escolar às peculiaridades do contexto rural de cada região (BRASIL, 2007).

Especificamente nos anos de 1997 e 1998 aconteceram importantes eventos que consolidam a Educação do Campo enquanto proposta de uma educação diferenciada para esse espaço. Um deles foi o I Encontro Nacional de Educadores/as da Reforma Agrária - I ENERA, dando o início à articulação das diferentes experiências de Educação do Campo. Em seguida, a criação do Programa Nacional de Educação na Reforma Agrária (PRONERA) objetivou fortalecer a educação nas áreas de Reforma Agrária, contribuindo para a promoção do desenvolvimento sustentável (BRASIL, 2004). E, finalmente, a Conferência Nacional de Educação do Campo, questionadora da memória coletiva e individual do camponês e do descontexto dos conteúdos dos livros didáticos às regionalizações culturais, buscando formas construtivas de valorizar a imagem desse espaço (ARROYO; FERNANDES, 1999). 
Outros momentos importantes ocorreram em 2004. O primeiro deles foi a criação da Secretaria de Educação Continuada, Alfabetização, Diversidade e Inclusão SECADI, estando vinculada à Coordenação de Educação do Campo, a qual era responsável pelo atendimento das demandas e inclusão social, principalmente dos povos do campo (BRASIL, 2007). Conforme o Caderno da SECADI 2, do Ministério da Educação, este órgão contribuiu para superar a precariedade presente nas escolas rurais, através de ações dirigidas à infraestrutura física, à efetividade da legislação da Educação do Campo, à promoção de seminários estaduais, ao fomento à produção acadêmica e ao incentivo à formação inicial e continuada de educadores, tendo como público-alvo jovens e agricultores familiares.

Mediante as atividades potencializadas pela SECADI, o segundo acontecimento no ano de 2004 foi a realização da Conferência Nacional de Educação do Campo, proposta pelo Movimento Nacional de Educação do Campo, a Confederação Nacional dos Trabalhadores na Agricultura - CONTAG e as demais organizações de pequenos agricultores e trabalhadores rurais. A discussão partiu do tema: 'Educação do Campo: Direito de todos, dever do estado!', pressionando o governo a formular políticas de universalização, e o vínculo da Educação do Campo aos interesses da agricultura camponesa (CALDART, 2012).

Em 2008, mais uma conquista foi atingida: o estabelecimento das Diretrizes Complementares, Normas e Princípios para a Educação do Campo. Esse documento define como sujeitos principais dessa categoria: os agricultores familiares, extrativistas, pescadores artesanais, ribeirinhos, assentados e acampados da Reforma Agrária, quilombolas, caiçaras, indígenas e outros (BRASIL, 2008).

Nesse contexto, também recebe destaque o Fórum Nacional de Educação do Campo (FONEC), ocorrido em 2010. Seu objetivo era retomar a articulação dos movimentos sociais e sindicais, destacando a participação de universidades e institutos federais, onde todos se colocaram contra o fechamento de escolas rurais, o modelo do agronegócio e a criminalização dos movimentos sociais (FÓRUM NACIONAL DE EDUCAÇÃO DO CAMPO, 2010).

Entretanto, com a troca de governo em 2019, o decreto n० 9.465 de 2 de janeiro vem a extinguir a Secretaria de Educação Continuada, Alfabetização e Diversidade SECADI (BRASIL, 2019). Tal ação representou uma das maiores barbáries executadas pela atual administração federal, pois estreitou o reconhecimento da diversidade, promoção e fortalecimento da inclusão na educação pública brasileira.

Os motivos que levaram a essa decisão convergem com os argumentos de que esse órgão era um complexo de setorização política capaz de intensificar a fragmentação das questões educacionais, a ausência de editais específicos para a criação dos cursos de Licenciatura em Educação do Campo e o corte orçamentário de verbas (ARAÚJO; BEZERRA, 2014). Dentre estes, o maior impacto recaiu no Programa Nacional de Educação em Áreas de Reforma Agrária (Pronera), onde houve uma redução de 70 para 3 milhões no período de 2008 a 2018 (ARAÚJO; BOGO, 2019). Além disso, segundo esses autores, cresceram os índices de fechamento das escolas rurais e de amparo às populações do campo. 
SOLIGO, S. C.; ODY, L. C.

Tendo como base essa cronologia, o modelo educacional destinado às classes campesinas se fundamenta na tríade: Campo, Educação e Política Pública. Estes elementos são fundamentais para a sua existência e materialização, além de inseparáveis na conjuntura prática (CALDART, 2008). Referindo-se ao Campo, ele se caracteriza pela dinâmica do ambiente, onde os sujeitos desenvolvem as relações de vida. Para Fernandes (2006), este território é marcado diretamente pela influência do capital na organização da agricultura. O segundo elemento, a Educação, está ligada aos debates articulados pelos movimentos sociais no processo histórico de luta territorial. Sua essência busca superar o monólogo do ensino rural e urbano adotado nas escolas públicas. Ou seja, as ações devem ser protagonizadas coletivamente, levando a desencadear processos que contribuam com a mudança da realidade e das práticas educativas (MOLINA, 2010). Como último termo do conjunto tem-se as Políticas Públicas, as quais são importantes para a superação da exclusão dos povos camponeses dos processos escolares. Os exemplos mais recentes destinados a esses grupos são: PROCAMPO - Programa de Apoio às Licenciaturas em Educação do Campo, estabelecido em 2007, e o PRONACAMPO - Programa Nacional de Educação do Campo, finalmente estabelecido em 2012 (MOLINA, 2003; SANTOS; SILVA, 2016). Ambos promoveram a inclusão de grande parte da população campesina no ensino universitário.

Assim, podemos afirmar que a Educação do Campo tem seus traços próprios e não se enquadra no modelo urbanocêntrico aplicado em espaços escolares rurais. Isso revela a importância em construir uma escola voltada às necessidades do trabalhador, a partir do entendimento da complexa realidade vivenciada cotidianamente.

\section{PROJETOS SOCIAIS: REALIDADES E INTERESSES}

Vivemos num mundo onde o conhecimento científico está cada vez mais presente nos diferentes modos de vida. Nesse sentido, reafirmar a importância da escola se vincula à ideia de preparo do estudante para compreender o seu espaço, e assim transformar o coletivo local (BRASIL, 2017).

O desafio de se educar, levando-se em conta os espaços escolares onde se desenvolvem certos processos educativos, passa pelo esforço em aproximar o saber sistematizado ao contexto de vida dos educandos e aos saberes que de lá brotam. Apesar de verificarmos em muitos discursos a importância dessa aproximação, percebemos certo afastamento entre as propostas educacionais presentes nos espaços escolares e a realidade dos estudantes, principalmente considerando o contexto do campo.

Vem ganhando destaque, no atual cenário educacional, a introdução de projetos escolares, que podem ser desenvolvidos por toda rede, individualmente em cada escola ou também em parcerias com outras instituições. Inclusive, o setor empresarial pode fomentar o desenvolvimento de atividades nas escolas, o que é estabelecido através da Lei de Responsabilidade Social das Sociedades Empresariais, ${ }^{3} \mathrm{n}^{\circ}$ 1.305/2003 (BRASIL, 2003).

Se fizermos uma busca na literatura existente, podemos encontrar uma infinidade de propostas desenvolvidas nos espaços escolares brasileiros. Alguns exemplos são encontrados no trabalho de Junqueira e Bezerra (2013), que apresenta as intervenções executadas pela Ação Brasileira do Agronegócio de Ribeirão Preto (ABAG - 
$\mathrm{RP})$, trazendo a teoria e prática através da interdependência campo - cidade, por meio do projeto Agronegócio na escola; a União da Indústria de Cana-de-Açúcar (UNICA), abordando as mudanças climáticas e as energias limpas por meio do programa Agora; e a transnacional Syngenta, com o plano Escola no Campo - Educação Ambiental no meio rural.

Ao explorar o projeto Agronegócio na Escola, desenvolvido pela Ação Brasileira do Agronegócio de Ribeirão Preto - SP (ABAG-RP), vemos que as ações já contemplaram, durante os anos de 2001 a 2019, um montante de 255.651 alunos e 3.307 professores. Seu objetivo era evidenciar a valorização das atividades agroindustriais presentes nas comunidades onde os estudantes residem (ABAG - RP, 2019). Segundo as informações dessa entidade, a metodologia de trabalho se centraliza em torno de visitas que alunos e professores realizam nos complexos agroindustriais, o que possibilita conectar a teoria e a prática na produção de alimentos, e ainda mobilizar intervenções educativas nesses locais.

De outra forma, a União da Indústria de Cana-de-Açúcar (UNICA) trabalha o projeto Agora. Este, lançado em 2009, já atendeu 12 mil escolas públicas de Mato Grosso do Sul, Minas Gerais, Bahia, Rio de Janeiro, São Paulo, Distrito Federal e Paraná, dirigindo-se principalmente a alunos de $8^{\circ}$ e $9^{\circ}$ anos (UNICA, 2011). Conforme essa instituição, as ações são desenvolvidas no âmbito da temática "Energias limpas", através da distribuição de materiais educativos cujo objetivo é mostrar a cana-de-açúcar como uma das protagonistas energéticas do país e evidenciá-la como grande fonte de riqueza ao país.

Já a Syngenta desenvolve o programa "Escola do Campo" desde $1991 \mathrm{em}$ parceria com a Secretaria de Educação do Estado de São Paulo. O objetivo deste é formar novas gerações de agricultores capazes de preservar o meio ambiente usando a tecnologia como meio de produção de alimentos saudáveis, de acordo com Junqueira e Bezerra (2013). Ainda segundo esses autores, a metodologia promissora para a companhia trabalhar a temática da Educação Ambiental no meio rural concentrou-se no uso de palestras técnicas aos estudantes, trazendo discussões sobre como plantar sem degradar o ambiente.

Como podemos perceber, a grande maioria dessas ações sociais voltadas ao meio escolar tem a natureza como ponto central para o desenvolvimento das suas atividades. Nesse sentido, ao debatermos a Ciência, é importante atentarmos aos interesses dos grupos econômicos presentes no meio escolar, já que, ao serem competitivos no mercado, tendem a disseminar a omissão do cuidado com a natureza, pois os valores que predominam nesse meio não são aqueles que têm o respeito à natureza como prioridade.

Por esse ângulo, a consolidação de tais parcerias pode levar uma série de questões importantes para os diversos aspectos envolvidos quando o objetivo é interferir nos processos educativos na escola. Por essa razão, é importante nos perguntarmos: Quais são seus propósitos? Em que pressupostos ideológicos estão fundamentados? Quem são os formadores? Tais aspectos, que raramente são conhecidos, acabam por interferir na dinâmica escolar e direcionam a formação dos alunos para um caminho que não considera o meio social onde eles estão inseridos, mas 
SOLIGO, S. C.; ODY, L. C.

prioriza aspectos globais que obedecem a princípios capitalistas e a produção de mão de obra para empresas que têm seus interesses voltados à produtividade e à lucratividade. Ficam em segundo plano os aspectos educacionais relativos à formação do cidadão a partir das disciplinas voltadas às humanidades, às artes ou a outras áreas do conhecimento não vinculadas diretamente com a questão do saber dirigido à produção de bens materiais.

Relativo a esses questionamentos, é plausível articularmos o propósito da inserção dos projetos desenvolvidos pela Lei de Responsabilidade Social ao aprofundamento do pensamento hegemônico capitalista na educação. Embora muitas propostas tragam estratégias lúdicas, tecnológicas e coletivas, os interesses são voltados ao setor empresarial que apenas reelabora conceitos educativos, não priorizando a formação de um novo homem, e sim a doutrinação ao sistema excludente (VALLE; ARRIADA, 2012).

Quando olhamos para os formadores vinculados a esse tipo de projeto oriundo da parceria empresas/escolas, temos outra incerteza, a de estarem eles realmente preparados para oportunizarem as estratégias capazes de suprir as demandas educacionais, pois não os conhecemos profissionalmente. Todavia, supondo possuírem uma formação de cunho pedagógico, devem conhecer a dinâmica de um espaço escolar.

Articulado a essa ideia, é possível tomar como exemplo a obra de Sartori (2013), “Formação do professor em serviço: da (re) construção teórica e ressignificação da prática", onde o autor aponta que ser um ou se posicionar como formador requer que educador veja a escola como local de conhecimentos e desafios, como também a mesma não deve aceitar esquemas importados ou soluções fabricadas de imediato. Corroborando o autor citado, o estudo empírico de Costa, Oliveira e Azevedo (2018) evidencia que o formador deve ter a contextualização e a análise social como uma necessidade que envolve o ideal democrático para a construção de uma sociedade mais justa.

A partir dos autores citados no parágrafo anterior, podemos afirmar que a maioria desses profissionais infiltrados nas escolas do campo não conhece a dinâmica da comunidade local, ou seja, não poderia oportunizar estratégias de ensino que estejam contextualizadas com a perspectiva dessa localidade. No entanto, por terem o aval das secretarias de educação, passam a desenvolver suas ações.

Supomos que se esses educadores realizassem uma análise do contexto brasileiro das lutas camponesas, os mesmos discordariam das práticas a que são submetidos a repassar às escolas do meio rural. A crescente difusão desses projetos sociais acaba por colocar o campo como espaço de empreendedorismo individualista, onde a natureza acaba sendo explicada praticamente pela Ciência e a pluralidade é extinta.

Mesmo assim, não podemos voltar no tempo concebendo a Educação do Campo como a antiga Educação Rural, pois hoje temos amparo legal através do Decreto Lei 7.352/2010, que evidencia os seus princípios (BRASIL, 2010). Tratar desses no contexto dos projetos executados pelo agronegócio releva olharmos se realmente há o respeito pela valorização da identidade da escola, utilização de metodologias adequadas às necessidades da comunidade e a participação dos movimentos sociais camponeses, conforme está expresso no Artigo $2^{\circ}$ da legislação citada. 
Quando olhamos para outros trabalhos sobre os projetos sociais nas escolas do campo, como o de Lamosa (2013), Junqueira e Bezerra (2013) e Bogo (2016), percebemos a atuação massiva que os conglomerados do agronegócio realizam em determinadas áreas onde a produção agrícola é intensiva. Assim, atuar de modo direto nas escolas externaliza a dependência total ao modelo do agronegócio, ou seja, compactuar com uma escolarização que adapta o ser humano ao mundo do produtivismo, ao desenraizamento cultural do campo como ambiente de vida e, consequentemente, conduzir o homem a operário da cidade.

Essas intervenções se caracterizam como algo contraditório ao movimento da Educação do Campo, o qual cogita promover a luta de classes e a emancipação humana. Alcançar determinado objetivo só será possível quando adotarmos, em rede, concepções e métodos que permitam a inserção social e política dessa população, numa relação crítica capaz de discutir abertamente os vínculos entre campo e cidade, resistência e hegemonia (MARTINS; COELHO; MIRANDA, 2011).

Tais elementos são traços da proposta de Educação do Campo, onde a luta de classes é o pilar principal para a construção de uma pedagogia baseada na formação humana. Ou seja, trata-se de conquistar uma perspectiva omnilateral capaz de pensar possibilidades, materializar um trabalho educativo alinhado ao horizonte das contradições da realidade vivenciada (CALDART, 2020).

Ao compreendermos esse movimento, é necessário estarmos dispostos a construir essa proposta de educação que conduz o sujeito como alguém intelectual, capaz de aprender mediante a interação dos saberes científicos e populares. Esse é um processo denso, no qual devemos assumir posturas políticas e dialógicas, no qual a escola, o trabalho docente e o olhar sobre a realidade produzem o real conhecimento que é incapaz de ser esquecido e, ao mesmo tempo, fundamento para novas conquistas dos sujeitos do campo.

Apesar disso, não devemos perder as esperanças, mas considerar que a escola pública é a principal possibilidade de democratizar a educação para o trabalhador, que releva a pensá-la enquanto parte do meio onde a vida acontece. A abrangência desse horizonte possibilita materializar propostas capazes de entender os limites e as potencialidades desse espaço. Ou seja, a escola pública pode ser a própria protagonista para que os sujeitos saiam da condição de desprezo e se tornem emancipados e emancipadores de outros (RANCIÈRE, 2002).

Sustentando determinado argumento, podemos afirmar que ensinar as Ciências da Natureza na atualidade exige a unificação da teoria à prática, dos saberes do cotidiano aos testados pelos meios tecnológicos e rigorosos. Para Figueiredo (2004), é compreender como o conhecimento científico interfere nas relações com o mundo natural.

Portanto, tornar evidente a proximidade do conhecimento científico ao popular, o meio ambiente aos problemas locais no cotidiano escolar, comprova a real construção de uma educação preocupada com os anseios da sociedade, visto que aprender não é apenas se pautar em assimilar um conteúdo ideológico meramente transmitido, mas compreendê-lo como vinculado à vida, cumprindo o objetivo de formar um sujeito empenhado na luta pela igualdade e a participação social. 
SOLIGO, S. C.; ODY, L. C.

\section{CONSIDERAÇÕES FINAIS}

Diante dos desafios que o âmbito educacional vem enfrentando, refletir sobre a Educação do Campo significa continuarmos com a luta histórica que promoveu a garantia e a expressão das conquistas alcançadas, especialmente pela classe camponesa, algo que não é fácil devido à pressão enfrentada pelos interesses dominantes que acabam por interferir na legislação estabelecida pelo Estado.

Como podemos perceber, a própria Lei de Responsabilidade Social das Sociedades Empresariais provém dessa mediação, de um lado evidencia a inserção de vínculos de aprendizagem na educação pública e de outro traz os propósitos de expandir as concepções produtivas hegemônicas dentro das escolas. Portanto, antes das redes de ensino ou dos gestores escolares se aproximarem desses projetos, é importante conhecerem seus objetivos e o que de novo podem proporcionar.

Sendo assim, conhecer a escola do campo e o desenvolvimento do ensino das Ciências da Natureza é um dos passos para entendermos a dinâmica do território rural e a subordinação imposta pelos agentes externos exploradores das suas riquezas naturais, o que deve ser amplamente analisado, pois impacta na visão que o jovem do campo constrói acerca do seu local de origem, já que vivemos um cenário de aceleração do êxodo e da industrialização do meio rural.

Relativo a isso, adotar o processo de reflexão na rede pública de ensino significa estar compromissado com a valorização e a capacitação contínua dos docentes no sentido de valorizar a cultura local e os saberes que ali são produzidos. Além do mais, podemos ofertar uma educação pautada nos ideais da ótica camponesa, permeando práticas apropriadas a uma práxis condizente com esse contexto sócio escolar.

Artigo recebido em: 17/08/2020

Aprovado para publicação em: 30/12/2020

\section{RURAL EDUCATION AND SOCIAL PROJECTS: A VISION OF INTERESTS}

ABSTRACT: This study is located in the investigation between the relation of the social projects developed in the peasant schools by companies of the agroindustrial branch and the perspective of the class struggle proposed by the Rural Education movement. To develop it, we used the qualitative methodology based on the bibliographic analysis. We highlight the achievements of this modality in recent decades. However, we highlight the impacts that capitalist projects have on rural schools. In this sense, it is important that these institutions and their education networks, establish partnerships in order to enable their educators to establish practices to strengthen an education that is geared to peasant needs.

KEYWORDS: Rural School. Education. Hegemonic Thinking. Natural Sciences. 


\section{EDUCACIÓN DE CAMPO Y PROYECTOS SOCIALES: UNA VISIÓN DE INTERESES}

RESUMEN: Este estudio se ubica en la investigación entre la relación de los proyectos sociales desarrollados en las escuelas campesinas por empresas del ramo agroindustrial y la perspectiva de la lucha de clases propuesta por el movimiento de Educación Rural. Para su desarrollo se utilizó la metodología cualitativa basada en el análisis bibliográfico. Destacamos los logros de esta modalidad en las últimas décadas. Sin embargo, destacamos los impactos que los proyectos capitalistas tienen en las escuelas rurales. En este sentido, es importante que estas instituciones y sus redes educativas, establezcan alianzas para que sus educadores puedan establecer prácticas para fortalecer una educación orientada a las necesidades campesinas.

PALABRAS CLAVE: Escuela Rural. Educación. Pensamiento Hegemónico. Ciencias Naturales.

\section{NOTAS}

1 - Na década de 1980, além do Movimento dos Trabalhadores Sem Terra, outras organizações de cunho popular apoiam a discussão em torno da Educação do Campo, tais como: a Comissão Pastoral da Terra (CPT) e a Confederação Nacional dos Trabalhadores da Agricultura (CONTAG) (BRASIL, 2007).

2 - Ao tratar da construção educativa omnilateral, remetemo-nos ao conceito de educação omnilateral de Frigotto (2012), apontando-o no seu sentido de entender as dimensões humanas e nas condições para o seu desenvolvimento histórico, ou seja, a edificação do sujeito enquanto ser provido de uma vida corpórea material, intelectual, cultural, educacional, afetiva, psicossocial e lúdica.

3 - A Lei no 1.305/2003 obriga as empresas nacionais e estrangeiras, cujo número de empregados seja superior a quinhentos, a proporcionar o fortalecimento das relações ambientais e comunitárias onde há o impacto com suas atividades (BRASIL, 2003).

\section{REFERÊNCIAS}

AÇÃO BRASILEIRA DO AGRONEGÓCIO DE RIBEIRÃO PRETO - ABAG. Programa educacional Agronegócio na Escola. 2019. Disponível em: $<$ https://www.abagrp.org.br/programa-educacional-agronegocio-na-escola $>$. Acesso em: 01 jan. 2021.

ARAÚJO, D. A. de C.; BEZERRA, G. F. Novas (re) configurações no Ministério da Educação: entre o fio de Ariadne e amortalha de Penélope. Revista Brasileira de Educação, Rio de Janeiro, v. 19, n. 56, jan./mar. 2014. p. 101-122.

ARAÚJO, L. de A.; BOGO, M. N. R. de. A Educação com Campo no contexto da política educacional brasileira atual. In: JORNADA INTERNACIONAL DE POLÍTICAS públicas, 9., 
SOLIGO, S. C.; ODY, L. C.

2019, São Luís. Anais eletrônicos... São Luís: UFMA, 2019. Disponível em: $<$ http://www.joinpp.ufma.br/jornadas/joinpp2019/images/trabalhos/trabalho_submissa old_1362_13625cc9a04a52133.pdf>. Acesso em: 02 jan. 2021.

ARROYO, M.; FERNANDES, B. M. A Educação Básica e o Movimento Social do Campo. Brasília: Articulação Nacional por uma Educação Básica do Campo, 1999.

BOGO, M. N. R. A. O agronegócio e a educação para as comunidades rurais na região extremo sul da Bahia: Desafios a luta social. Germinal, Salvador, v. 8, n. 2, p. 23 - 28, dez. 2016.

BRASIL. Projeto Lei no 1.305 / 2003, de 24 de junho de 2003. Dispõe sobre a Responsabilidade Social das Sociedades Empresariais. Lex: Coordenação de Comissões Permanentes - DECOM. Brasília, DF, 24. jun. 2003. Suplemento. Disponível em: <http://www.camara.gov.br/proposicoesWeb/prop_mostrarintegra;jsessionid=28B81D9 45BAABD4FDFCC29F4A109766C.node2?codteor $=258194 \&$ filename=Avulso+$\underline{P L+1305 / 2003}>$. Acesso em: 03 set. 2018.

BRASIL. Ministério do Desenvolvimento Agrário. Manual de operações: PRONERA. Brasília: MDA, 2004.

BRASIL. Ministério da Educação. Educação do Campo: diferenças mudando paradigmas. Cadernos SECAD 2. Brasília: MEC, 2007.

BRASIL. Resolução CNE/CEB no 2, de 28 de abril de 2008 - Estabelece as Diretrizes Complementares, Normas e Princípios para o Desenvolvimento de Políticas Públicas de atendimento da Educação Básica do Campo. Diário Oficial da União: Art.1º, Brasília, DF, 2 abr. 2008.

BRASIL. Decreto - lei no 7.352, de 4 de dezembro de 2010. Dispõe sobre a política de Educação do Campo e o Programa Nacional de Educação na Reforma Agrária PRONERA. Diário Oficial [da] República Federal do Brasil, Brasília, DF, 4 dez. 2010. Disponível em: <https://www2.camara.leg.br/legin/fed/decret/2010/decreto-7352-4novembro-2010-609343-norma-pe.html>. Acesso em: 02 jan. 2021.

BRASIL. Ministério da Educação. Base Nacional Comum Curricular: ensino fundamental. Brasília: MEC/SEB, $2017 . \quad$ Disponível em: $<$ http://basenacionalcomum.mec.gov.br/images/BNCC_El_EF_110518_versaofinal_site. pdf >. Acesso em: 02 set. 2018.

BRASIL. Decreto no 9.465, de 2 de janeiro de 2019. Aprova a estrutura regimental e o quadro demonstrativo dos cargos e da comissão das funções do Ministério da Educação. Diário Oficial [da] União, Poder Executivo, Brasília, DF, 2 jan. 2019. Seção 1, p. 6.

CALDART, R.S Sobre a educação do campo. In: SANTOS, C. (org.). Educação do Campo: campo - políticas públicas - educação. Brasília: INCRA; MDA, 2008. p. 67-86. 
CALDART, R. S. Educação do Campo. In: CALDART, R. S. PEREIRA, I. B.; ALENTEJANO, P.; FRIGOTTO, G. (orgs.). Dicionário de Educação do Campo. Rio de Janeiro; São Paulo: Escola Politécnica de Saúde Joaquim Venâncio: Expressão Popular, 2012. p. 259-262.

CALDART, R. S. A Educação do Campo e a construção da pedagogia socialista. In: GOULART, A. J. et al. (orgs.). Diálogo sobre Educação do Campo: resistência e emancipação social e humana. Curitiba: Appris, 2020. p. 53-65.

CECHIN, R. VIEIRA, M. M. M. O Curso Técnico em Agropecuária: histórico e perfil dos alunos e egressos. 2004. Disponível em: $<$ http://coral.ufsm.br/sifedocregional/images/Anais/Eixo\%2004/Raul\%20Cecchin\%20e\% 20Marilandi\%20Maria\%20Mascarello\%20Vieira.pdf.> Acesso em: 25 ago. 2018.

COSTA, R. F.; OLIVEIRA, R. de C.; AZEVEDO, H. H. O. de. Professores e sua formação no mundo capitalista. Revista Perspectiva em Educação, Viçosa, v. 9, n. 1, p. 142-158, jan./abr. 2018.

FERNANDES, B. M. Os campos a pesquisa em Educação do Campo: espaço e território como categorias essenciais. In: MOLINA, M. C. Educação do Campo e Pesquisas: Questões para reflexão. Brasília: Ministério do Desenvolvimento Agrário - MDA, 2006. p. 27-39.

FIGUEIREDO, M. de. A ciência escolar como instrumento para a compreensão da atividade científica. 2004. Tese (Doutorado em Educação) - Faculdade de Educação, Universidade Federal de Minas Gerais, Belo Horizonte, 2004.

FÓRUM NACIONAL DE EDUCAÇÃO DO CAMPO. Carta de criação do Fórum Nacional de Educação do Campo. Brasília: FONEC, 2010.

FRIGOTTO, G. Educação Omnilateral. In: CALDART, R. S.; PEREIRA, I. B.; ALENTEJANO, P.; FRIGOTO, G. (orgs.). Dicionário da Educação do Campo. Rio de Janeiro / São Paulo: Escola Politécnica de Saúde Joaquim Venâncio, Expressão Popular, 2012. p. 267 - 273.

GADOTTI, M. M. Educação Popular, Educação Social, Educação Comunitária - conceitos e práticas diversas, cimentadas por uma causa comum. Revista Diálogos: pesquisa em formação universitária, Brasília, v. 18, n. 1, p. 10-32, dez. 2012.

GRITTI, S. M. Técnico em agropecuária: servir à agricultura familiar ou ser desempregado da agricultura capitalista. 2007. 252 f. Tese (Doutorado em Educação), Faculdade de Educação, Universidade Federal do Rio Grande do Sul, Porto Alegre, 2007.

JUNQUEIRA, V. H.; BEZERRA, M. C. dos S. Projetos educacionais do agronegócio: campo e cidade em questão. In: SEMINÁRIO DO GRUPO DE ESTUDOS E PESQUISAS SOBRE EDUCAÇÃO NO CAMPO, 1., 2013, São Carlos. Anais eletrônicos [...]. São Carlos: UFSCar, 
SOLIGO, S. C.; ODY, L. C.

2013. Eixo temático: Educação do Campo, Movimentos Sociais e Políticas Públicas, p. 117. Disponível em: <http://www.gepec.ufscar.br/publicacoes/publicacoes-seminariosdo-gepec/seminarios-de-2013/1-educacao-do-campo-movimentos-sociais-e-politicaspublicas/a32-projetos-educacionais-do-agronegocio-campo-e.pdf/at_download/file>. Acesso em: 12 ago. 2020.

LAMOSA, R. de A. C. O Programa Agronegócio na escola: um estudo sobre a entrada do empresariado na escola pública. In: SIMPÓSIO NACIONAL DE HISTÓRIA, 27, 2013, Natal. Anais eletrônicos [...]. Natal: ANPUH, 2013. Disponível em: $<$ http://www.snh2013.anpuh.org/resources/anais/27/1364343743_ARQUIVO_ArtigoAN PUH2013final.pdf>. Acesso em: 2 jan. 2021.

MARTINS, M. de F. A.; COELHO, A. M. S.; MIRANDA, S. A. Desafios e possibilidades da área de Ciências Sociais e Humanidades na Formação para a docência no campo. In: ANTUNES - ROCHA, M. I.; MARTINS, A. A. Educação do Campo: desafios para a formação de professores. 2 ed. Belo Horizonte: Autêntica, 2011. p. 95-106.

MOLINA, M. C. A contribuição do PRONERA na construção de políticas públicas de educação do campo e desenvolvimento sustentável. 2003. Tese. (Doutorado em Desenvolvimento Sustentável) - Centro de Desenvolvimento Sustentável, Universidade de Brasília, Brasília, 2003.

MOLINA, M. C. Desafios Teóricos e Práticos na Execução das Políticas Públicas de Educação do Campo. In: MUNARIM, A. et al. (org.). Educação do Campo: reflexões e perspectivas. Florianópolis: Insular, 2010. p. 103-121.

OMETTO, A. M. H.; FURTUOSO, M. C. O.; SILVA, M. V. da. Economia brasileira na década de oitenta e seus reflexos nas condições de vida da população. Revista Saúde Pública, São Paulo, v. 29, n. 5, p. 403-414, 1995.

RANCIÈRE, J. O mestre ignorante: cinco lições sobre emancipação intelectual. Tradução Lilian do Valle. Belo Horizonte: Autêntica, 2002. 144 p.

SANTOS, R. B.; SILVA, M. A. Políticas públicas em educação do campo: Pronera, Procampo e Pronacampo. Revista Eletrônica de Educação, São Carlos, v. 10, n. 2, p. 135-144, 2016.

SANTOS, M. Educação do Campo no Plano Nacional de Educação: tensões entre a garantia e a negação do direito à educação. Ensaio: Avaliação Políticas Públicas Educacionais, Rio de Janeiro, v. 26, n. 98, p. 185-212, jan./mar. 2018.

SARTORI, J. Formação do professor em serviço: da (re)construção teórica e ressignificação da prática. Passo Fundo: Editora da Universidade de Passo Fundo, 2013.

TIEPOLO, E. V. Paulo Freire e a luta pela educação no MST. In: EDUCERE - CONGRESSO NACIONAL DE EDUCAÇÃO, 12., 2015, Curitiba. Anais eletrônicos [...]. Curitiba: PUCPR, 2015. Disponível em: 
$<$ https://educere.bruc.com.br/arquivo/pdf2015/20854_11371.pdf $>$. Acesso em: 2 jan. 2020.

UNIÃO DA INDÚTRIA DE CANA - DE - AÇÚCAR - UNICA. Relatório Final do Projeto Agora: estudo dos municípios canavieiros 2011. São Paulo: Editora Horizonte, 2011.

VALLE, H. S. do; ARRAIADA, E. Makarenko e Pistrak: uma análise da pedagogia social do trabalho. Revista Portuguesa de Pedagogia, Coimbra, v. 46, n. 1, p. 109-125, 2012.

Silas Cleiton Soligo: Possui bacharelado em Agronomia pelo Instituto de Desenvolvimento Educacional do Alto Uruguai - IDEAU (2013). Licenciado em Educação do Campo: Ciências da Natureza pela Universidade Federal da Fronteira Sul UFFS (2018). Mestre em Educação por esta mesma universidade (2020).

Orcid: 0000-0002-7397-1102

E-mail: silas.soligo@yahoo.com

Leandro Carlos Ody: Graduado em Filosofia pela Universidade de Passo Fundo - UPF (2001). Mestre em Filosofia pela Universidade Federal de Santa Catarina - UFSC (2005). Doutor em Educação pela Universidade de Passo Fundo - UPF (2015). Professor da Universidade Federal da Fronteira Sul - UFFS - Campus Erechim nos cursos Interdisciplinar em Educação do Campo: Ciências da Natureza e no Mestrado Profissional em Educação, atuando também como coordenador adjunto desse programa.

Orcid: 0000-0001-7785-3077

E-mail: leandro.ody@uffs.edu.br

Este periódico utiliza a licença Creative Commons Attribution 3.0, para periódicos de acesso aberto (Open Archives Initiative - OAI). 